\title{
COMPLETE AMINO ACID SEQUENCE OF a-ACETOLACTATE DECARBOXYLASE FROM BACILLUS BREVIS
}

\author{
by \\ IB SVENDSEN, BIRGER ROSTGAARD JENSEN ${ }^{1)}$ and MARTIN OTTESEN ${ }^{2)}$ \\ Carlsberg Laboratory, Department of Chemistry, \\ Gamle Carlsberg Vej 10, DK-2500 Copenhagen Valby \\ 1) Novo Industry A/S, Novo Allé, DK-2880 Bagsvaerd \\ 2) Present address: Anfangervej 6, Fensmark, DK-4700 Næstved
}

Keywords: Beer maturation

The complete amino acid sequence of acetolactate decarboxylase (EC 4.1.1.5) from Bacillus brevis has been determined by sequencing of the intact enzyme and of peptides obtained by cleavage with cyanogen bromide, Staphylococcus aureus $\mathrm{V} 8$ protease and trypsin, respectively. Determination of the C-terminal part was made by treatment with carboxypeptidases $Y$ and M II. The enzyme has a molecular weight of 29.093 and consists of 260 amino acid residues arranged in a single peptide chain without disulphide bonds.

\section{INTRODUCTION}

The rate limiting step in beer maturation is the non-enzymatic oxidative decarboxylation of $\alpha$ acetolactate to diacetyl. One way of accelerating beer maturation is to add acetolactate decarboxylase to fermenting or maturing beer and thereby rapidly convert $\alpha$-acetolactate to acetoin which contrary to diacetyl does not give an off-flavour to the beer $(3,4,5,6)$. An enzyme isolated from Bacillus brevis has been used successfully in laboratory experiments, but nothing is known about the mechanism by which the enzyme operates. As an initial step in elucidating the structure-function relationship of the enzyme the primary structure has been determined by conventional amino acid sequencing using automated Edman degradation.

\section{MATERIALS AND METHODS}

\subsection{Materials}

Acetolactate decarboxylase (ALDC) was isolated from Bacillus brevis as described below. $\mathrm{S}$. aureus V8 protease was from ICN Immuno Biologicals, Lisle, Ill., USA and trypsin type XI from Sigma, St. Louis, USA. Carboxypeptidase $Y$ was from Carlbiotech, Copenhagen, Denmark and carboxypeptidase MII was purified in Department of Chemistry, Carlsberg Laboratory. Reagents and solvents used in sequencing

Abbreviations: ALDC = acetolactate decarboxylase; CPD-MII = carboxypeptidase II from malt; CPD-Y = carboxypeptidase $Y$ from yeast; TFA $=$ trifluoro acetic acid. 
were from Applied Biosystems, Foster City, Cal., USA. S-Sepharose FF, PBE 96, Sephadex G 25 SF, Mono-P HR 5/20, Superose 12 HR 10/30 and Polybuffer 96 were from Pharmacia, Uppsala, Sweden. Biogel P60 and Bio-Rad Protein Assay were products of Biorad, Richmond, Cal., USA and Vydac $C_{18}$ obtained from The Separation Group, Hesperia, Cal., USA. All other chemicals were of the highest purity obtainable and "Milli Q" water was used throughout. Ultrafiltration equipment was from Amicon Corp., Danvers, Mass., USA.

\subsection{Methods}

\subsubsection{Extraction and purification of $A L D C$}

Bacillus brevis ATCC 11031 was grown on a complex medium composed of yeast extract, corn steep liquor, hydrolyzed casein, hydrolyzed soybean meal and glutaminate. Cells were harvested from a continuous $(\mathrm{d}=0.2)$ fermentation broth by centrifugation on a SAMS centrifuge at a speed of 1200 liters per hour. The sludge was homogenized in a Manton Gaulin homogenizer at 550 bar and extracted at $\mathrm{pH} 7$ with four volumes of water. Following clarification by filtration the extract was concentrated by ultrafiltration to $1.5 \%$ of the original fermentation broth volume. The concentrated extract was germ filtered and finally spray-dried. The activity yield was $6.5 \%$.

$120 \mathrm{~g}$ of spray-dried whole cell extract was suspended in $600 \mathrm{ml}$ water and $\mathrm{pH}$ was adjusted to 4.6 with acetic acid $(700 \mathrm{ml}, 171.5 \mathrm{U} / \mathrm{ml}, 2.07$ $\mathrm{U} / \mathrm{mg}$ prot.). The mixture was kept at $50^{\circ} \mathrm{C}$ for 30 minutes. After centrifugation the supernatant was dialyzed against $0.05 \mathrm{M}$ ammonium acetate $\mathrm{pH} 4.8$. The retentate was filtered $(0.45$ $\mu$ ) and applied onto a column of S-Sepharose FF ( $800 \mathrm{ml}, 5 \mathrm{~cm}$ diam., $10 \mathrm{ml} / \mathrm{min}$ ) equilibrated with the same buffer. The column was washed with starting buffer ( 11 l) and the activity was eluted with an ammonium acetate gradient 0.05-1.5 M (total vol. 4 1). The enzymatically active fractions were pooled $(840 \mathrm{ml}) . \mathrm{pH}$ was adjusted to 6.0 and the pool was first concentrated on an Amicon hollow-fiber cartridge (H1P10-20) and finally in a stirred cell (PM 10 membrane) to $19 \mathrm{ml}(2950 \mathrm{U} / \mathrm{ml}, 46.4 \mathrm{U} / \mathrm{mg}$ prot., step yield $46.7 \%$ ).
$17 \mathrm{ml}$ was dialyzed against $0.025 \mathrm{M} \mathrm{MES} \mathrm{pH}$ 6.1. After centrifugation and filtration $(0.45 \mu)$ the sample was passed through a $40 \mathrm{ml}$ column of PBE 96. The flow-through was collected and concentrated to $9.5 \mathrm{ml}$ in a stirred ultrafiltration cell $(3072 \mathrm{U} / \mathrm{ml}, 134.7 \mathrm{U} / \mathrm{mg}$ prot., step yield $63.3 \%)$.

Buffer exchange to $0.025 \mathrm{M}$ Tris $\mathrm{pH} 8.3$ (acetic acid) was done on an $80 \mathrm{ml}$ column of Sephadex G $25 \mathrm{SF}$. The protein fraction $(30 \mathrm{ml})$ was applied on a Mono-P HR 5/20 at a flowrate of $0.5 \mathrm{ml} / \mathrm{min}$. The column was washed with 0.025 M Tris pH 8.3 and then eluted with Polybuffer 96 $(0.0075 \mathrm{mmol} / \mathrm{pH} / \mathrm{ml}) \mathrm{pH} 6.2$ with acetic acid. The three most active fractions were pooled ( 3 $\mathrm{ml}, 4687 \mathrm{U} / \mathrm{ml}$, step yield $51.8 \%$, no prot. determination).

Polybuffer was removed by gelfiltration on Superose 12 HR 10/30 (flowrate $0.5 \mathrm{ml} / \mathrm{min}, 0.2$ $\mathrm{M}$ ammonium acetate $\mathrm{pH} 6.0$ ). $0.3 \mathrm{ml}$ was applied in each run. The pooled fractions contained $1192 \mathrm{U} / \mathrm{ml}, 1610 \mathrm{U} / \mathrm{mg}$ prot., step yield $84.4 \%$. Total yield was $12.9 \%$. The preparation was homogeneous as judged by SDS-PAGE.

Enzyme activity was determined as described earlier (6). The Bio-Rad Protein Assay was used with ovalbumin as protein standard.

\subsubsection{Cleavage with cyanogen bromide}

To $170 \mu \mathrm{g}$ (6 nanomoles) of ALDC were added $2 \mathrm{mg}$ of cyanogen bromide in $70 \%$ formic acid and the reaction mixture was left overnight in the dark at room temperature. The resulting peptides were separated on $\mathrm{C}_{18}$ column (Vydac 218TP54) using a Water's HPLC system with $0.1 \%$ TFA and a linear gradient in acetonitril from 0 to $60 \%$ in $90 \mathrm{~min}$. Relevant peaks were collected, dried under vacuum (in a Savant Speed Vac Concentrator) and sequenced.

\subsubsection{Digestion with $S$. aureus V8 protease}

To $170 \mu \mathrm{g}$ (6 nanomoles) of ALDC dissolved in $400 \mu \mathrm{l}$ of $0.1 \mathrm{M} \mathrm{NH}_{4} \mathrm{HCO}_{3}, \mathrm{pH} 7.8$ and $\mathrm{S}$. aureus V8 protease was added in the ratio 1:20 (w/w). The mixture was left af $40{ }^{\circ} \mathrm{C}$ in a water-bath with stirring for $6 \mathrm{hrs}$. The resulting peptides were separated as described under 2.2.2. 


\subsubsection{Digestion with trypsin}

To $170 \mu \mathrm{g}$ (6 nanomoles) of ALDC dissolved in $400 \mu \mathrm{l} 0.1 \mathrm{M} \mathrm{NH}_{4} \mathrm{HCO}_{3}, \mathrm{pH} 7.8$, was added trypsin in the ratio 1:100 (w/w) and the mixture left overnight with stirring at room temperature. The resulting peptides were separated as described under 2.2.2.

\subsubsection{Amino acid analysis}

The amino acid composition of the intact enzyme was determined by acid hydrolysis in $5.7 \mathrm{M} \mathrm{HCl}$ for 24,48 and $72 \mathrm{hrs}$ at $110^{\circ} \mathrm{C}$ in sealed and evacuated tubes and in duplicate. In those cases where sufficient material was available, 24 hrs analyses were conducted with peptides obtained from cleavage with chemicals or enzymes as described in 2.2.2 to 2.2.4. A Durrum 500 amino acid analyzer was used.

\subsubsection{Amino acid sequencing}

An Applied Systems Sequenator model 470A, equipped with an on-line HPLC, Applied Systems model 120A PTH Analyzer, was used for determining the amino acid sequences of intact protein and peptides. Program no. 03CPTH supplied by the manufacturer was used.

\subsubsection{Digestion with carboxypeptidases}

In order to determine the C-terminal sequence of ALDC, $4.5 \mathrm{nmol}$ of the C-terminal peptide obtained by cleavage with cyanogen bromide was dissolved in a $50 \mathrm{mmol}$ sodium acetate buffer $\mathrm{pH}$ 4-5 and first treated with CPD-MII for $30 \mathrm{~min}$ at room temperature (ratio $1: 199 \mathrm{w} / \mathrm{w}$ ), whereafter an aliquot was removed for analyses of free amino acids. The reaction mixture was subsequently treated with CPD-Y for $30 \mathrm{~min}$ (ratio 1:100) during which period aliquots were removed at suitable time intervals for amino acid analysis. In all cases the enzymatic reaction was stopped by addition of $\mathrm{HCl}$ to pH 2.

\subsubsection{Sequence alignment and prediction of secondary structure \\ Sequence comparison with ALDC from E.}

aerogenes was made manually while the prediction of secondary structure was done using the programme PREDICT from the Protein Sequence Database of PIR.

\section{RESULTS AND DISCUSSION}

The amino acid sequence of 260 residues shown in Figure 1 was obtained from sequencing of the intact enzyme and peptides obtained by cleavage with cyanogenbromide, $S$. aureus, strain V8 protease, and trypsin. Of the peptides sequenced only those necessary to obtain overlaps are included in the figure.

$\mathrm{N}$-terminal sequencing of the enzyme gave rise to two sequences, one starting at Thrl and the other starting at Thr4. The enzyme thus has a "ragged" N-terminal which conceivably is the result of proteolytic activity taking place during purification.

Amino acid sequences of peptides obtained by cleavage with cyanogen bromide which were of importance for the construction of the total sequence were Leu39-Met57, Leu123-Met144 and Val145-Lys166. In the first two cases the peptide was sequenced to the end and a peak always appeared in the same position as PTHThr on the HPLC chromatograms. It has not been shown whether this peak corresponds to PTH-homoserine or its lactone. However, since PTH-homoserine will be more hydrophilic that its lactone it is most likely PTH-homoserine which is observed eluting from the reversed phase column at this position. Sequences of peptides obtained from cleavage with $\mathrm{S}$. aureus V8 protease were Ser14-Asp45 (indicating incomplete cleavage at Glu43), Met69-Pro89 (indicating incomplete cleavage at Glu87), Ser91Glu106, Lys107-Leu119, Asn129-GIn153, Phe172-Thr202, Asp204-Glu222 and Phe229. Ala255. Finally, the following sequences of peptides obtained from cleavage with trypsin are included in Figure 1: Asn26-Ala36, Gly55Met69, Leu85-Lys93, Thr108-Lys121, Gln153Lys 173, Gly177-Lys205 and Thr206-His235.

It is apparent that two overlaps are missing in the sequence: between Glu 106 and Lys 107 and between Lys 121 and Leu 123. (The Met in position 122 is inferred from cleavage with cyanogen bromide.) However, comparison with a corre- 



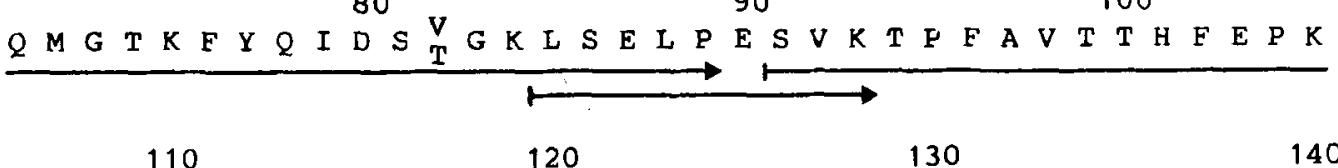

110

120

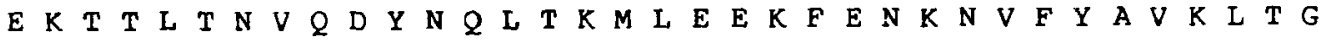

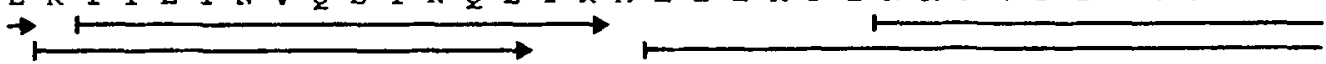

150

160

170

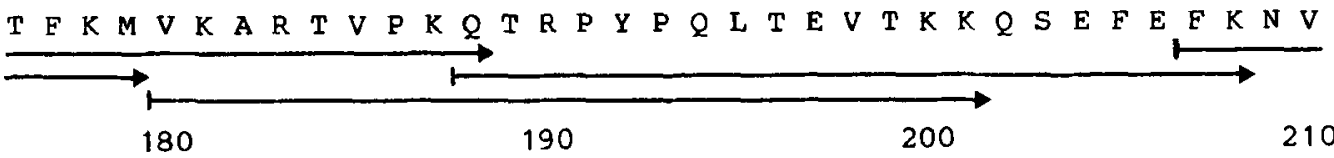

K G

V L N L Q F D N A N L E I S P I H E F D V Q L P H T D D F A H S D L T

$\underset{\text { QVT QS Q V H A E S E R K }}{\longrightarrow}$

Figure 1. The amino acid sequence of acetolactate decarboxylase from Bacillus brevis. $\mapsto$ indicates start of sequencing and number of residues sequenced. $\downarrow$ indicates the alternative starting point in $\mathrm{N}$-terminal sequencing of intact protein. Polymorphism was observed in positions 33 and 82.

sponding amino acid sequence obtained from nucleotide sequencing (1) showed that no additional amino acids exists.

Attempts to determine the C-terminal of ALDC on the intact protein failed. However, using the C-terminal cyanogenbromide fragment Val145-Lys260 (Fig. 1) gave the result shown in Figure 2. It is clear that Lys is the C-terminal residue followed by an Arg. However, it was difficult to place the Ser relative to the two Glu. Ser was placed in position 257 after comparison with the translated nucleotide sequence (1).

Comparison of the amino acid sequence of ALDC determined directly with that derived from the corresponding nucleotide sequence (1) shows identity except for three positions. Gln249 found in this study is Thr249 in the nucleotide sequence. $\mathrm{Thr}$ was found in position 33 with both methods, but in addition amino acid sequencing of the tryptic peptide starting at Asn 26 showed a Gly in position 33 . However, no Gly was observed when the S. aureus V8 peptide starting at Ser 14 was sequenced. Finally, in one case where the $\mathrm{CNBr}$ peptide starting at Gly 73 was sequenced, a Thr as well as a Val were found in position 82 . This microheterogeneity thus indicates that more than one gene codes for ALDC in B. brevis.

Another nucleotide sequence corresponding 




Figure 2. Determination of the $\mathrm{C}$-terminal amino acid sequence of acetolactate decarboxylase by digestion with carboxypeptidase MII followed by carboxypeptidase $Y$. The liberated amino acid residues are given by the one letter code. For details see text.

to acetolactate decarboxylase from Enterobacter aerogenes (9) has also been sequenced. A comparison between that and the one described in the present investigation is shown in Figure 3. The two enzymes are of approximately the same length the $B$. brevis enzyme extending two residues further in the $\mathrm{C}$-terminal end compared to the one from E. aerogenes. It has not been necessary to introduce gaps in order to obtain a homology of $31 \%$ ( 86 residues in identical positions). No similarity between the sequences is observed for the $\mathrm{N}$-terminal 23 residues or the $15 \mathrm{C}$-terminal residues. On the contrary, strong homology is observed in the regions Gly55Ile70, Lys93-Pro 104, Arg148-Tyr157 and Asn 192-Leu212. Nothing is known about which amino acid residues are involved in the catalytic function of ALDC. It is known, however, from well characterized families of enzymes that amino acid sequences around catalytic active residues are well preserved. It is therefore reasonable to assume that the functional amino acid residues of ALDC may be found in the homologous regions mentioned above.

If it is speculated that the reaction mechanism in ALDC is the same as found with acetoacetate decarboxylase where an intermediate Schiffbase is formed with an $\varepsilon$-amino group of an essential lysyl residue $(7,8)$ it is noteworthy to compare the numbers and positions of the lysyl residues in the two ALDC's for which the amino acid sequences are known. While ALDC from $B$. brevis has 23 Lys and only 4 Arg the ALDC from E. aerogenes has only 5 Lys, but 15 Arg (Table I). When the two sequences are compared only position 93 has a Lys in both enzymes which is located N-terminal in a highly homologous sequence. Thus, if the two ALDC's operate by the mechanism suggested in part above, Lys 93 is likely the essential amino acid.

Table. I. Amino acid composition of ALDC from B. brevis and $\mathbf{E}$. aerogenes.

\begin{tabular}{lccc}
\hline Amino acid & \multicolumn{2}{c}{ B. brevis } & E. aerog. ${ }^{3)}$ \\
\hline Asx & $27.10^{1)}$ & $27^{2)}$ & $29^{2)}$ \\
Thr & 28.20 & 28 & 15 \\
Ser & 11.28 & 11 & 18 \\
Glx & 35.00 & 34 & 29 \\
Pro & 20.86 & 16 & 13 \\
Gly & 15.00 & 14 & 18 \\
Ala & 16.52 & 17 & 21 \\
1/2 Cys & 0 & 0 & 4 \\
Val & 19.15 & 17 & 14 \\
Met & 5.27 & 6 & 7 \\
Ile & 8.26 & 8 & 11 \\
Leu & 25.26 & 24 & 24 \\
Tyr & 6.74 & 7 & 7 \\
Phe & 15.76 & 16 & 15 \\
His & 9.69 & 8 & 12 \\
Arg & 3.24 & 4 & 15 \\
Lys & 23.38 & 23 & 5 \\
Trp & 0 & 0 & 1 \\
\hline Total & & 260 & 258 \\
\hline
\end{tabular}

1)From amino acid analysis.

2) From amino acid sequence.

${ }^{3)}$ From ref. (9).

One striking difference is seen between the two ALDC's in Figure 3. While the enzyme from E. aerogenes contains four Cys in positions 6, 8, 13 and 134, the one from $B$. brevis is devoid of Cys residues. It is not known whether the four Cys in the E. aerogenes enzyme are present as free Cys or as two disulfide bridges, but in ALDC from $B$. brevis the tertiary structure must been maintained by other means as is known from another group of bacterial enzymes, the subtilisins. 


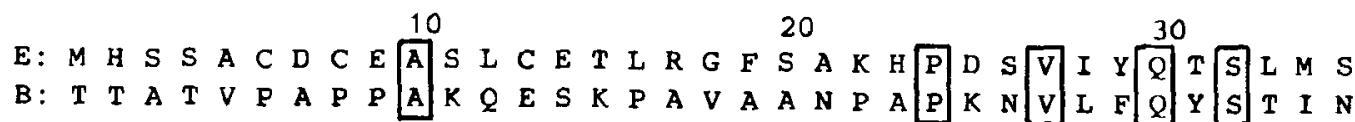

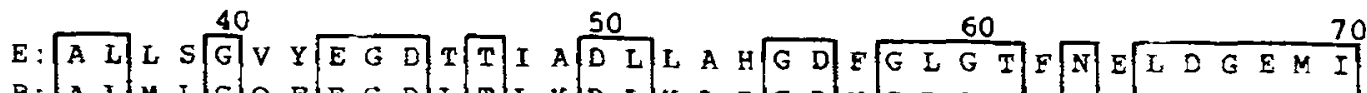

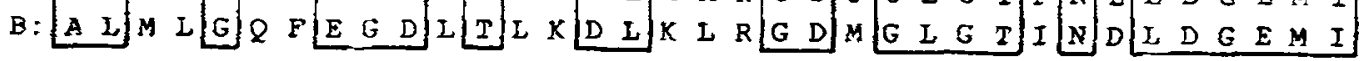

E: A F S S Q

E: A F S S Q V V Y Q L $\begin{aligned} & 80 \\ & \text { I A }\end{aligned}$

B: $Q$ M $M$ G

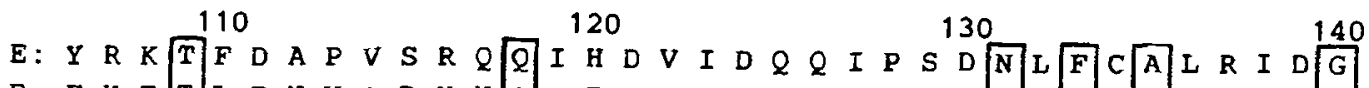

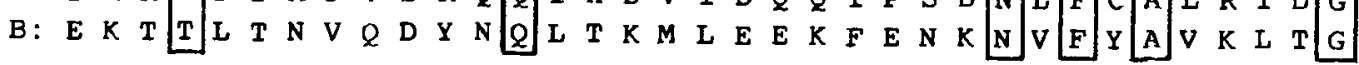

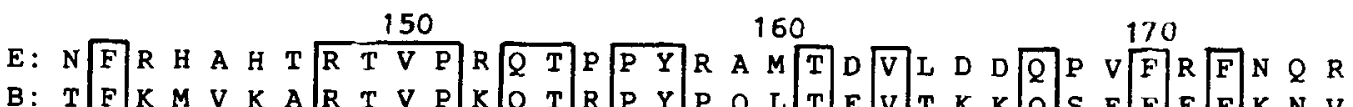

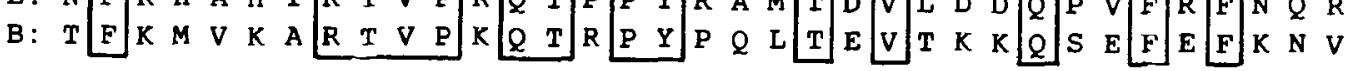

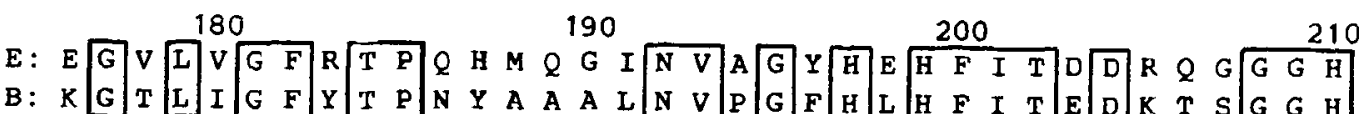

E: $\quad$ L

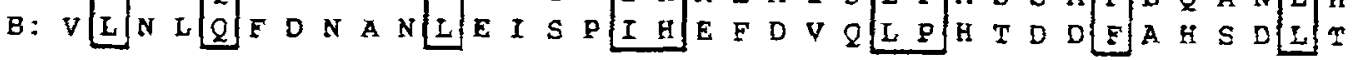

250

260

E: P S N L D A A I R S Y EN

B: $Q V$ T Q S Q V H Q A ESERK

Figure 3. Comparison of the amino acid sequence of acetolactate decarboxylase of Bacillus brevis (B) with that obtained from nucleotide sequencing of the corresponding enzyme from Enterobacter aerogenes (E) (9). Residues in identical positions are boxed. The sequence of the E. aerogenes enzyme may be two Met residues longer in the $\mathrm{N}$-terminal since the starting position of the amino acid sequence has not been determined.

Predictions of the secondary structure by the method of GARNIER et al. (2) indicate a highly ordered structure of ALDC from B. brevis. $54 \%$ is predicted as being $\alpha$-helix and $34 \%$ as being $\beta$-sheets. The corresponding figures for ALDC from $E$. aerogenes are also $54 \%$ helix and $34 \%$ $\beta$-sheet.

The molecular weight calculated on the basis of the amino acid sequence is 29.093 . In SDSPAGE the enzyme appears to have a molecular weight of 35.000 and in gelfiltration experiments 70.000 indicating that under native conditions ALDC appears as a dimer. Since ALDC does not contain any carbohydrate the rather large discrepancy between the calculated and experimentally determined molecular weight is difficult to explain.

\section{ACKNOWLEDGEMENTS}

Drs. SVEnd Ludvigsen and TORBEN G. PEDersen are thanked for help in the computerassisted comparison of sequences. Mss. BODIL Corneliussen, Pia Breddam, Lone Sørensen, Pia Wium Sørensen and Ulla Rosenberg ate gratefully acknowledged for expert technical assistance. 


\section{REFERENCES}

1. Diderichsen, B.. U. Wedsted, L. HedegaARd, B.R. JENSEN \& C. SJøHOLM: Cloning of an unusual exoenzyme: $\alpha$-acetolactate decarboxylase from Bacillus brevis. (To be published)

2. GARNIER, J., D.J. OSGUTHORPE \& B. RoBson: Analysis of the accuracy and implications of simple methods for predicting the secondary structure of globular proteins. J. Mol. Biol. 120, 97-120 (1978)

3. GodTFREDSEN, S.E. \& M. OTTESEN: Maturation of beer with $\alpha$-acetolactate decarboxylase. Carlsberg Res. Commun 47, 93-102 (1982)

4. GodTfRedsen, S.E., H. LoRCK \& P. SigsgaARd: On the occurrence of $\alpha$-acetolactate decarboxylases among microorganisms. Carlsberg Res. Commun. 48, 239-247 (1983)

5. GodtrRedsen,S.E., A.M.RASMusSen, M.OTtesen, P. RAFN \& N. PEITERSEN: Occurrence of $\alpha$-acetolactate decarboxylases among lactic acid bacteria and their utilization for maturation of beer. Appl. Microbiol. Biotechnol. 20, 23-28 (1984)

6. JENSEN, B.R., I. SVENDSEN \& M. OTTESEN: Isolation and characterization of an $\alpha$-acetolactate decarboxylase useful for accelerated beer maturation. Proc. Congr. - Eur. Brew. Conv. 21, 545-552 (1987)

7. LAURSEN, R.A. \& F.H. WeSTHEIMER: The active site of acetoacetate decarboxylase. J. Amer. Chem. Soc. 88, 3426-3430 (1966)

8. Lederer, F., S.M. CoutTS, R.A. LAURSEN \& F.H. WESTHEIMER: Acetoacetate decarboxylase. Subunits and properties. Biochemistry 5, 823-833 (1966)

9. Sone, H., T. Fuji, K. Kondo, F.SHimizu,J. TANaKa \& I. TAKASHI: Nucleotide sequence and expression of the enterobacter aerogenes alpha-acetolactate decarboxylase gene in brewer's yeast. Appl. Environ. Microbiol. 54, 38-42 (1988)

Accepted by E. LuND 